\title{
Bazalt Kumaşların Bazı Isıl Özelliklerinin Son Kullanım Açısından Değerlendirilmesi
}

\author{
Çağlar Sivri ${ }^{1 *}$ \\ 1* Bahçeşehir Üniversitesi, Mühendislik ve Doğa Bilimleri Fakültesi, İşletme Mühendisliği Bölümü, İstanbul, Türkiye, (ORCID: 0000-0001-5829-2796), \\ caglar.sivri@eng.bau.edu.tr
}

(İlk Geliş Tarihi Aralık 2020 ve Kabul Tarihi Ocak 2021)

(DOI: 10.31590/ejosat.846954)

ATIF/REFERENCE: Sivri, Ç. (2021). Bazalt Kumaşların Bazı Isıl Özelliklerinin Son Kullanım Açısından Değerlendirilmesi. Avrupa Bilim ve Teknoloji Dergisi, (22), 27-31.

$\ddot{O} z$

Bu çalışmada, önceki çalışmalardaki eksikliklerden yola çıkılarak, bazalt lifinden mamül kumaşların termal iletkenlik ve termal direnç analizlerinin yanısıra termal soğurganlık ve kalınlık gibi parametreleri son kullanım açısından giyim, otomotiv, izolasyon, güçlendirme ve filtrasyon gibi farklı uygulama alanlarına göre değerlendirilmiştir. Çalışma esnasında Ukrayna kaynaklı kayalardan elde edilmiş bazalt kumaşı, tahribatsız test prensibiyle çalışan Alambeta cihazı kullanılarak termal açıdan iletkenlik, direnç, soğurganlık ve kalınlık parametrelerinin ölçümü gibi birkaç farklı analize tabi tutulmuştur. Bu analizlere göre yüksek termal direnç gösteren bazalt kumaşının giyim alanında kullanımı için tek başına kullanımı yerine bir kompozit yapının içinde kullanılmasının daha uygun olacağı sonucuna varılmıştır. Yine bu analizlere göre Otomotiv uygulamalarında izolasyon kapasitesinin arttırılabilmesi için dokuma kumaş yerine dokunmamış yüzey olarak kullanımının daha uygun olacağı sonucuna varılmıştır. Genel bir değerlendirme yapıldığında ise bazalt kumaşının birçok uygulama alanı için uygun ve ideal bir malzeme olduğu ancak her bir alan için termal açıdan iletkenlik ve direnç özelliklerinin, soğurganlık ve kalınlık özellikleriyle birlikte hatta gerekli görülen yerlerde kütle transferi testlerinin de bu testlere ilaveten yapılması gerektiği sonucuna varılmıştır.

Anahtar Kelimeler: Bazalt, Kumaş, Termal analiz, Mühendislik uygulamaları.

\section{Evaluation of Some Thermal Properties of Basalt Fabrics in Terms of End Use}

\begin{abstract}
In this study, based on the shortcomings of previous studies, thermal conductivity and thermal resistance analyzes as well as thermal absorptivity and thickness parameters of fabrics made of basalt fiber were evaluated in terms of end use according to different application areas such as clothing, automotive, insulation, reinforcement and filtration. During the study, the basalt fabric obtained from the rocks of Ukraine was subjected to several different analyzes such as the measurement of thermal conductivity, resistance, absorptivity and thickness parameters using the Alambeta device, which works with the non-destructive test principle. According to these analyzes, it was concluded that it would be more appropriate to use basalt fabric with high thermal resistance in a composite structure instead of using it alone for clothing. Again, according to these analyzes, it was concluded that it would be more appropriate to use it as a nonwoven surface instead of woven fabric in order to increase the insulation capacity in automotive applications. When a general evaluation is made, it is concluded that basalt fabric is a suitable and ideal material for many application areas, but for each area, thermal conductivity and resistance properties, absorbency and thickness properties, as well as mass transfer tests where necessary, should be performed together in addition to these tests.
\end{abstract}

Keywords: Basalt, Fabric, Thermal analysis, Engineering applications.

*Sorumlu Yazar: caglar.sivri@eng.bau.edu.tr 


\section{Giriş}

Bazalt lifleri son kulanım açısından oldukça yüksek termal stabilite, korozyona dayanıklı yapıs1, 1sıl izolasyon performans1, gürültü sönümleme, düşük nem emicilik, yüksek mukavemet ve modüler performansından ötürü birçok uygulama için geleceğin malzemesi olarak nitelendirilmektedir (Wei vd., 2011). Uygulamalar özelinde, otomotivde aşınma ve sürtünme sönümleme ile 1sıl izolasyon, inşaatta güçlendirme malzemesi, havacılık ve uzay araçları ile deniz araçlarının gövde güçlendirmesi, elektro-teknik alanda elektromanyetik kalkanlama ve filtre alanında yüksek 1sıda gaz filtrasyon fonksiyonuyla kullanımı günden güne artmaktadır (Militky, 2002; Sim, 2005; Singha, 2012; Wang vd., 2008).

Birçok açıdan yüksek performans gösteren basalt lifi her ne kadar çok farklı uygulamalar için ideal bir malzeme olsa da en çok 1sıl dayanım ve ateşe dayanıklı ürün geliştirme uygulamalarında kullanım alanı bulmaktadır ve bu durum akademi ve endüstride yapılan çalışmaların bu alana yoğunlaşmasından da anlaşılmaktadır.

Li ve arkadaşları bazalt lifinin efektif biçimde ve mukavemet özelliğini yitirmeden bir tesisin sıvı oksijen üretim bölümünde termal izolasyon malzemesi olarak kullanıldığından bahsetmişlerdir (Li vd., 2018). Başka bir çalışmada araştırmacılar bazalt lifini cam lifi ile karşılaştırmış ve yüksek sıcaklık uygulandıktan bazalt lifinin mukavemet kalıcılığının cam lifine göre oldukça yüksek olduğunu bildirmişlerdir (Ying \& Zhou, 2013).

Yukarıda bahsi geçen araştırmalar bazalt lifinin endüstriyel uygulamaları gibi daha çok giyim dışı kullanımları için yapılan çalışmaları kapsamaktadır. Oysa bazalt lifinin sadece aleve dayanıklılık ya da yanmazlık özellikleri dışında bilhassa giyim alanında da kullanılabilecek termal iletkenlik ve termal direnç gibi özellikleri mevcuttur ve özellikle de koruyucu giysi ya da tekstil esaslı koruyucu ekipman geliştirme açısından büyük potansiyel taşımaktadır. Bu konuya ilişsin araştırmacılar bazalt lifinin ve bazalt lifinden mamül kumaşın termal iletkenlik değerini ölçümlemişler ve diğer malzemelere görece daha düşük iletkenlik değerine sahip olduğunu bulmuşlar ve bu durumu düşük lif çapı ile açıklamışlardır (Borshakova \& Kostenok, 1995). Diğer bir çalışmada araştırmacılar \%100 bazalt lifinden mamül kumaş üzerinde termal iletkenlik ve termal direnç testleri uygulamışlar ve özellikle Polipropilen ve Jüt bazlı tekstil kumaşları ile karşılaştırıldığında en yüksek termal direnç ve en düşük termal iletkenliğe sahip olduğu bulgusu ile bazalt lifi esaslı kumaşların koruyucu tekstil geliştirilmesi açısından yüksek düzeyde uygunluğu sonucuna varmışlardır (Jamshaid vd., 2016).

Literatürdeki çalışmalardan anlaşılabileceği üzere bazalt lifi üzerine yapılan sınırlı sayıda çalışmalarda yanmazlık dışında termal özellik analizleri yapılmış ve bu çalışmalarda özellikle termal direnç ve termal iletkenlik parametrelerine ağırlık verilmiştir. Özellikle giysi alanı için termal parametreler bu iki parametre ile sınırlı değildir. Termal direnç ve termal iletkenlik parametrelerine ek olarak termal soğurganlık ve ısıl akış gibi parametreler de özellikle bazalt lifinden koruyucu tekstil yüzeyi geliştirilmesi açısından önem taşımaktadır. Bu çalışmada bazalt lifinden mamül kumaşın termal direnç, termal iletkenlik, termal soğurganlık ve ısıl akış gibi farklı parametreleri deneysel olarak analiz edilmiş ve son kullanım alanı açısından yorumlanmıştır.

\section{Materyal ve Metot}

\subsection{Materyal}

Bu çalışmada Ukrayna kaynaklı kayalardan üretilmiş basalt kumaş, Çek Cumhuriyeti Liberec Teknik Üniversitesi tarafından sağlanmıştır. Şekil 1'de görüldüğü gibi doğal parlak bir görünüme sahiptir. Bazalt, volkanlardan dökülen katılaşmış lavın genel adıdır. Bazalt kayaçlar yaklaşık olarak 1500-1700 ${ }^{\circ} \mathrm{C}$ aralığında eritilir. $\mathrm{Bu}$ eriyik hızla söndürüldüğünde cam gibi katılaşır ve büyük ölçüde amorf bir yapıya sahip olur. Yavaş soğutma gerçekleştirilirse, bu durum morfolojide az çok tam kristalleşmeye sebep olur (Fu vd., 2020).

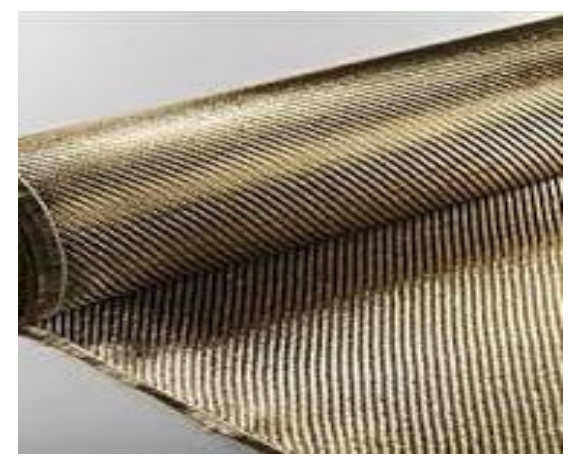

Şekil 1. Bazalt kumaşının görüntüsü

Çalışmada Liberec Teknik Üniversitesi tarafından sağlanan bazalt kumaş multifilament esaslıdır ve genel özellikleri Tablo 1 'de verilmiştir.

Tablo 1. Bazalt Kumaş Numunesine Ait Öznitelikler

\begin{tabular}{l|l}
\hline Doku & Dimi 3/1 \\
\hline Görünüm & Doğal parlak \\
\hline Gramaj (g/m²) & 385 \\
\hline Kalınlık (mm) & 0,4 \\
\hline Atkı sıklığı (adet/cm) & 10 \\
\hline Çözgü sıklığı (adet/cm) & 10 \\
\hline
\end{tabular}

Malzeme özellikleri ve kumaş konstrüksiyonu kumaşların son uygulama özellikleri ve özellikle de termal performansı açısından da büyük önem taşımaktadır ve bu çalışmanın devamında planlanan termal kütle transfer özelliklerine etkisi araştırılacaktır (Guney vd., 2019).

\subsection{Metot}

$\mathrm{Bu}$ çalışmada bazalt kumaşının bazı termal özellikleri son uygulamalar açısından incelenmiştir. Bazalt kumaşının termal özelliklerinin ölçümü için Çek Cumhuriyeti Sensora firmasının üretimi Alambeta cihazı kullanılmıştır. Elde edilen sonuçların grafik halinde görselleştirilmesi OriginPro 9 programı ile yapılmıştır. 
Bazalt kumaşının termal iletkenlik, termal direnç, termal soğurganlık ve kalınlık değerleri, numunelere tahribatsız bir şekilde test yapabilen Alambeta cihazı kullanılarak ölçülmüştür (Şekil 2). Cihazın ölçüm prensibi birkaç temel adımdan ibarettir. Ölçüm başlar başlamaz, sensörlü 1S1 algılama bloğunu içeren ölçüm kafası aşağı iner ve alet tabanında bulunan ölçüm numunesine dokunur. $\mathrm{Bu}$ anda, numunenin yüzey sicaklığ aniden değişir ve cihaz daha sonra 1 sı güç rotasını kaydeder ve farklı sınır koşullarına maruz kalan ince plaka üzerindeki geçici sıcaklık alanını çözer. Tüm bu değişimler analiz edildikten sonra cihazın ekranında termal iletkenlik, termal direnç, termal soğurganlık ve kalınlık değerleri sayısal olarak okunur. Tekstil kumaşları için termal iletkenlik $\lambda[\mathrm{W} / \mathrm{m} . \mathrm{K}]$, 1sının kumaş yüzeyinden başka bir yüzeye iletilmesi işlevini temsil eder. Termal direnç $r\left[\mathrm{~m}^{2} \mathrm{~K} / \mathrm{W}\right]$, iletkenliğin aksine, bir tekstil kumaşının 1sı alışverişini en aza indiren ve yalıtım işlevi sağlayan bir parametredir. Termal soğurganlık $b\left[\mathrm{~W} \mathrm{~s} \mathrm{~s}^{1 / 2} / \mathrm{m}^{2} \mathrm{~K}\right]$ yeni bir sicak-serinlik hissi parametresidir; bu değer yüksek olduğunda kumaşlar serinlik hissi verirken, düşükken sıcaklık hissi verir. Kalınlık h [mm] değeri termal parametrelerle çok ilgili bir değerdir; genellikle tekstil yüzeylerinin kalınlığı arttıkça termal direnci de artar (Dolezal vd., 2019). Bu çalışma dahilinde bazalt kumaşının 10 farklı bölgesinden 10 tekrar ölçüm alınarak

\section{Araştırma Sonuçları ve Tartışma}

$\mathrm{Bu}$ çalışmada Alambeta cihazı kullanılarak bazalt esaslı kumaşa zarar verilmeden termal iletkenlik $(\lambda)$, termal direnç $(r)$, ölçülen her bir parametre için toplamda 100 değer elde edilmiştir ve sonrasından her bir değer 10'a bölünmek suretiyle ortalaması bulunup tabloya eklenmiştir.

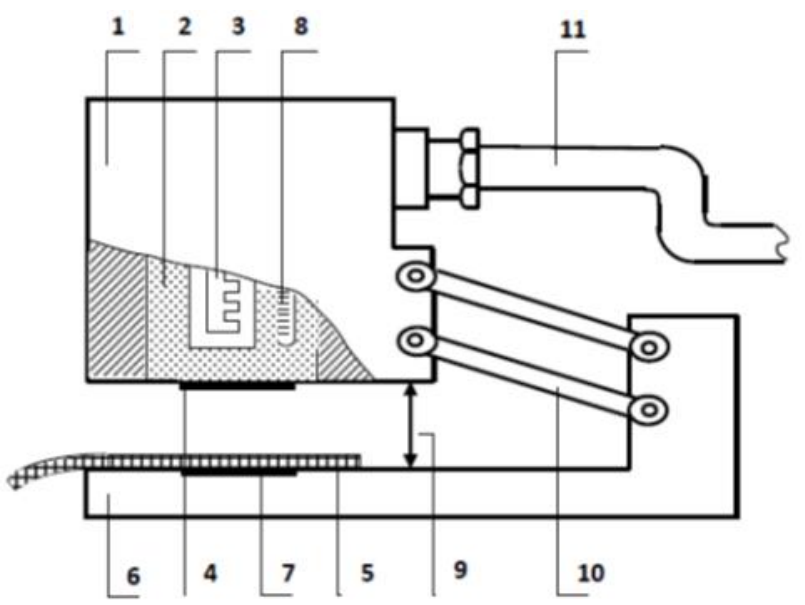

Şekil 2. Alambeta cihazının yandan görünüşü

(Hes and Dolezal, 2018)

termal soğurganlık (b) ve kalınlık (h) değerleri ölçülmüştür. Ölçülen değerlere ait sonuçlar Tablo 2'de verilmiştir.

Tablo 2. Bazalt Kumaş Numunesine Ait Termal Parametre Ölçüm Sonuçları

\begin{tabular}{c|c|c|c|c|c|c|c|c|c|c}
\hline & $\mathbf{1}$ & $\mathbf{2}$ & $\mathbf{3}$ & $\mathbf{4}$ & $\mathbf{5}$ & $\mathbf{6}$ & $\mathbf{7}$ & $\mathbf{8}$ & $\mathbf{9}$ & $\mathbf{1 0}$ \\
\hline$\lambda[\mathrm{W} / \mathrm{m} \cdot \mathrm{K}]$ & 41,7 & 42,5 & 43,4 & 43,5 & 44,1 & 44,2 & 44,4 & 44,9 & 46,2 & 46,5 \\
\hline $\mathrm{r}\left[\mathrm{m}^{2} \mathrm{~K} / \mathrm{W}\right]$ & 11,5 & 10,8 & 9,9 & 9,8 & 9,3 & 9,1 & 8,9 & 8,7 & 7,7 & 7,6 \\
\hline $\mathrm{b}\left[\mathrm{W} \mathrm{s}^{1 / 2} / \mathrm{m}^{2} \mathrm{~K}\right]$ & 164 & 175 & 189 & 191 & 199 & 201 & 204 & 209 & 222 & 224 \\
\hline $\mathrm{h}[\mathrm{mm}]$ & 0,46 & 0,43 & 0,4 & 0,39 & 0,38 & 0,37 & 0,36 & 0,35 & 0,3 & 0,29 \\
\hline
\end{tabular}

Tablo 2'de sunulan ölçüm sonuçlarına göre termal iletkenlik ve termal direnç ölçümlerine ilișkin elde edilen grafik Şekil 3'te verilmiştir.

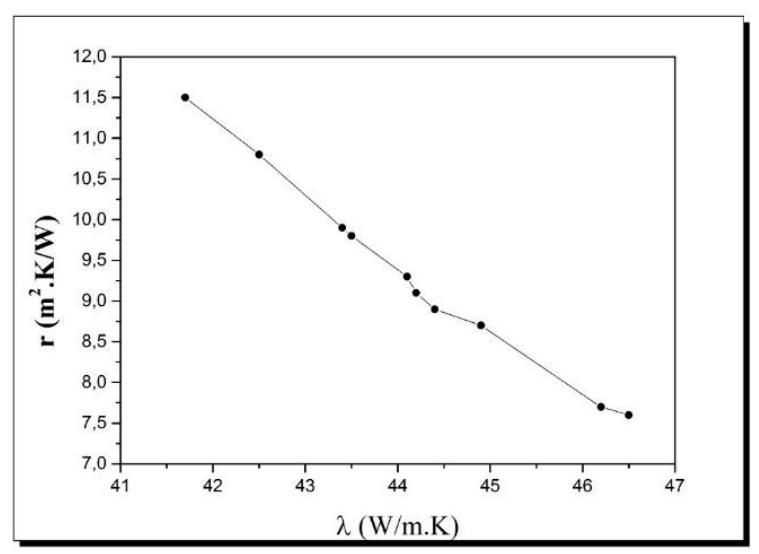

Şekil 3. Bazalt kumaşının termal iletkenlik ve termal direnç ölçüm sonuçlarına ilişkin grafik

Şekil 3'te görüldüğü üzere termal direnç değeri arttıkça termal iletkenlik değeri azalmaktadır. Bu grafik için hesaplanan $\mathrm{R}^{2}=0,987$ değeri ölçülen iki parametre arasında güçlü bir ilișki olduğunu göstermektedir. $\mathrm{Bu}$ sonuca göre bazalt kumaşının termal iletkenliğini düşürmek için termal direncinin arttırılması gerekliliği ortaya çıkmakta ve kumaşa bu yönde bir işlem uygulanma ihtiyacı söz konusu olmaktadır.

Tablo 2'de sunulan ölçüm sonuçlarına göre termal iletkenlik ve termal soğurganlık ölçümlerine ilişkin elde edilen grafik Şekil 4 'te verilmiştir. 


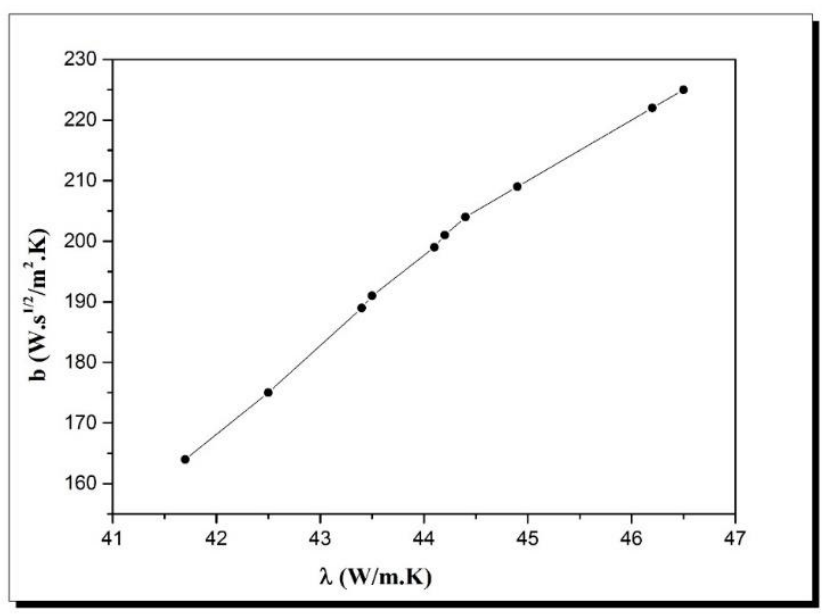

Şekil 4. Bazalt kumaşının termal iletkenlik ve termal soğurganlık ölçüm sonuçlarına ilişkin grafik

Şekil 4’te görüldüğü üzere termal iletkenlik değeri arttıkça termal soğurganlık değeri de artmaktadır. Bu grafik için hesaplanan $\mathrm{R}^{2}=0,9841$ değeri ölçülen iki parametre arasında güçlü bir ilişki olduğunu göstermektedir. Bu sonuca göre bazalt kumaşının termal iletkenlik değeri arttıkça kumaş serinlik hissi vermektedir.

Tablo 2'de sunulan ölçüm sonuçlarına göre termal iletkenlik ve kalınlık ölçümlerine ilişkin elde edilen grafik Şekil 5'te verilmiştir.

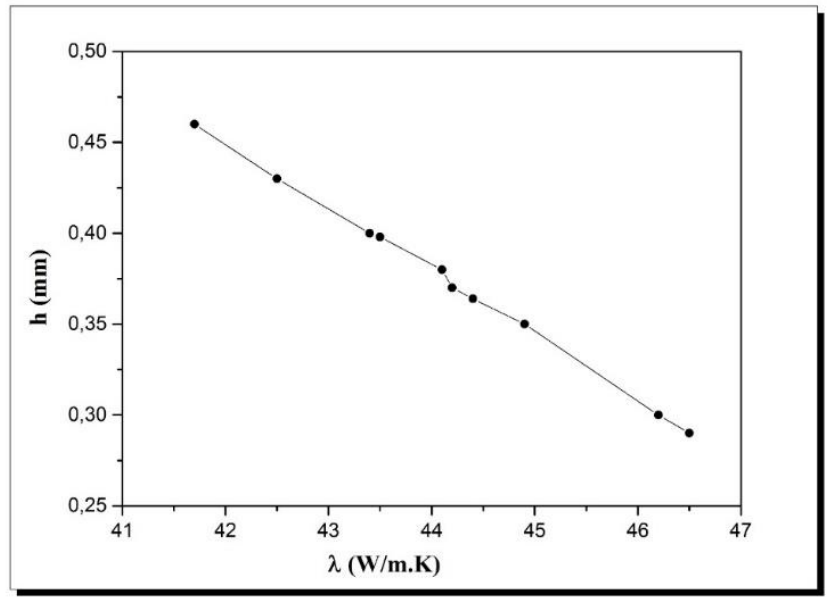

Şekil 5. Bazalt kumaşının termal iletkenlik ve kalınlık sonuçlarına ilişkin grafik

Şekil 5'te görüldüğü üzere bazalt kumaşının kalınlığı arttıkça termal iletkenlik değeri düşmektedir. Bu grafik için hesaplanan $\mathrm{R}^{2}=0,9962$ değeri ölçülen iki parametre arasında güçlü bir ilişki olduğunu göstermektedir. Bu sonuca göre daha ince bazalt kumaşlarının daha yüksek termal iletkenliğe sahip olduğu anlaşılmaktadır.

\section{Sonuç}

$\mathrm{Bu}$ çalışmada bazalt kumaşının bazı termal özellikleri Alambeta cihazı kullanılarak test edilmiştir. Bazalt kumaşlar son kullanım alanları açısından öncelikli olarak ısıya dayanım ve termal izolasyon amaçlı olarak kullanılmaktadır. Bu bağlamda çalışmanın sonuçları sırasıyla farklı uygulama alanlarına göre değerlendirilmiştir.
Giyim alanı açısından değerlendirildiğinde bazalt kumaşının termal direncinin artması ile termal iletkenliğinin azaldığı görülmüştür. Termal iletkenliğin düşüşü aynı zamanda düşük termal soğurganlığa sebep olmakta, yani giyen kişiye daha çok sıcaklık hissi vereceği anlamına gelmektedir. Yine bazalt kumaşının kalınlığı arttıkça termal iletkenliğinin düştüğü ve buna bağlı olarak giyen kişiye verdiği sicaklık hissinin arttığ görülmüştür. Bu sonuçlar değerlendirildiğinde, bazalt kumaşının özellikle yanmaya dayanıklı giyim eşyası olarak tek başına değil, çok katmanlı bir kompozit yapının özellikle vücuda temas etmeyen dış katmanına uygulanması gerek giyim konforu gerekse koruyuculuk fonksiyonu açısından daha doğru olacaktır.

Otomotiv alanı açısından 1sıl izolasyon fonksiyonu değerlendirildiğinde, termal iletkenliğinin düşmesiyle birlikte artan termal stabilite olası bir yangında malzemenin koruyuculuk özelliğini arttırdığı gibi, aracın 1sıtılması ya da soğutulmasında da maliyet düşüşü sağlayacaktır. Bu özellikleriyle bazalt lifinin otomotivde dokuma yerine dokunmamış yüzey formunda kullanılması izolasyon kapasitesi ve etkinliğini arttıracaktır.

Havacılık ve uzay araçları alanı açısından gövde güçlendirilmesi amacıyla kullanımı değerlendirildiğinde, bu uygulama güçlendirmenin yanısıra düşük termal iletkenliğin sağladığı termal stabilite ile birlikte özellikle ani 1S1 değişimlerinin söz konusu olduğu bu ortamda, araçlara uzun ömür ve dayanım sağlayacağı gibi bu değişimlerin getireceği anlık termal yükü de en aza indirecektir.

Gaz filtrasyonu alanında özellikle yüksek sıcaklıklarda işlem söz konusu olduğu için test sonuçlarından da görülebilen düşük termal iletkenlik ve termal soğurganlık değerleri yüksek derecede termal stabilite sağlayacak ve bu şekilde filtrasyon esansında olası risklerin önüne geçilmiş olacaktır.

Sonuçlar genel olarak değerlendirildiğinde bazalt lif kumaşlarının giyimden ulaşıma ve hassas filtrasyon uygulamalarına kadar çok geniş bir yelpazede kullanımı söz konusudur. Burada kritik husus bazaltın tek başına mı yoksa kompozit formunda bir yapının parçası olarak mı kullanılacağına ve uygulama alanına göre dokunmuş ya da dokunmamış yüzey gibi hangi formda kullanılacağına iyi karar verilmesi gereklidir.

$\mathrm{Bu}$ çalışmanın devamında bazalt kumaşların su buharı geçirgenliği ve hava geçirgenliği gibi diğer performans özellikleri test edilecek ve çeşitli uygulamalar açısından potansiyel etkileri değerlendirilecektir.

\section{Kaynakça}

Borshakova, N. V., Kostenok, O. M. (1995). Thermal conductivity of basalt fiber materials. Heat Engineering, 36, 9-10. Doi: 10.1007/BF02227481.

Dolezal, I., Hes, L., Bal, K. (2019). A non-destructive single plate method for measurement of thermal resistance of polymer sheets and fabrics. International Journal of Occupational Safety and Ergonomics, 25(4), 562-567. Doi: 10.1080/10803548.2018.1477247.

Fu, Hai-dong, Feng, Xin-ya, Liu, Jin-xu, Yang, Zhi-ming, He, C., Li, Shu-kui (2020). An investigation on anti-impact and penetration performance of basalt fiber composites with different weave and lay-up modes. Defence Technology, 16(4), 787-801. Doi: 10.1016/j.dt.2019.09.005. 
Güney, S., Balcı, H., Üçgül, İ. (2019). The Effect of fabric structural geometry on thermal transfer performance in sportswear. Avrupa Bilim ve Teknoloji Dergisi, (17), 711717. Doi: 10.31590/ejosat.629477.

Hes, L., Dolezal I. (2018). Indirect measurement of moisture absorptivity of functional textile fabrics. J. Phys.: Conf. Ser. 1065 122026. Doi:10.1088/1742-6596/1065/12/122026.

Jamshaid, H., Mishra, R., Militky, J. (2016). Thermal and mechanical characterization of novel basalt woven hybrid structures. The Journal of The Textile Institute, 107(4), 462471. Doi: 10.1080/00405000.2015.1034940.

Li, Z., Ma, J., Ma, H., Xu, X. (2018). Properties and applications of basalt fiber and its composites. IOP Conf. Ser.: Earth Environ. Sci, 186. Doi: 10.1088/1755-1315/186/2/012052.

Militky, J., Kovacic, V., Rubnerov, J. (2002). Influence of thermal treatment on tensile failure of basalt fibers. Eng Fract Mech, 69, 1025-1033. Doi: 10.1016/S00137944(01)00119-9.

Singha, K. (2012). A Short Review on Basalt Fiber. International Journal of Textile Science, 1(4), 19-28. Doi: 10.5923/j.textile.20120104.02.
Sim, J., Park, C., Moon, D. Y. (2005). Characteristics of basalt fiber as a strengthening material for concrete structures. Composites Part B: Engineering, 36, 504-12. Doi: 10.1016/j.compositesb.2005.02.002.

Wang X., Hu, B., Feng, Y., Liang, F., Mo, J., Xiong, J. (2008). Low velocity impact properties of 3D woven basalt/aramid hybrid composites. Compos Sci Technol., 68, 444-50. Doi: 10.1016/J.COMPSCITECH.2007.06.016.

Wei, B., Cao, H., Song, S. (2011). Surface modification and characterization of basalt fibers with hybrid sizings. Composites: Part A, 42, 22-29. Doi:10.1016/j.compositesa.2010.09.010.

Ying, S., Zhou, X. (2013). Chemical and thermal resistance of basalt fiber in inclement environments. J. Wuhan Univ. Technol. Mat. Sci. Edit., 28, 560-565. Doi: 10.1007/s11595013-0731-4. 